\title{
Automatic Records System at the University of Missouri Library
}

By RALPH H. PARKER

$I^{N}$ NSTALLATION of IBM equipment in the library of the University of Missouri in January 1957 was the first step in the development of an integrated automatic records system. The initial operations were planned to be self-sufficient but also to fit into further automation without major modification of records or procedures. In some cases, had no further extension of the system been contemplated, a different approach might have been preferable.

The extent to which the system will be expanded will depend upon future developments. If electronic computer use for information retrieval should be proven practicable, the present system can encompass that aspect, and the computer can be used for all other computations and records.

As installed in 1957, the equipment was to be used in fiscal operations only. It was planned to use the equipment for all ordering, paying, and accounting for library materials. Plans were also developed for preliminary cataloging records. Subscription records were already on IBM cards using equipment in the university business office, and were the first operation taken over in the library installation.

The key machine in the library is the IBM cardatype, Type 858. This machine reads standard IBM cards, and also receives input information from a keyboard; it is capable of adding, subtracting, and multiplying. Information read into or developed in the machine may be read out to a typewriter or a keypunch or both. It is possible to attach
Dr. Parker is Librarian, University of Missouri.

as many as four typewriters, each preparing distinctive documents.

To support the cardatype, there are another keypunch (Type 026), a sorter (Type 080), and a collator (Type 085). Since the punches also print, there is no need for an interpreter. This battery of equipment can perform almost any operation of which punched card equipment is capable. In addition to listing items and totals, the cardatype can double as a reproducer, summary punch, and gang punch.

The only difference from larger installations is speed, and in some cases the apparent slowness of the cardatype is illusory. An illustration will suffice. Subscriptions are recorded on punched cards which show title, expiration date, renewal period, source (vendor), estimated cost (previous year's cost), cost, and a number of other items. When the subscriptions to be renewed have been selected from the file by the collator and arranged by dealer by the sorter, and vendor address cards have been inserted in front of each group, the cardatype is used to type the purchase orders, automatically advancing the expiration date. If it is desired that the dealer should be changed, the only thing needed is to use the new dealer's address card. As a byproduct, a new accounting card is created, reflecting the data appearing on the order, including the new order date, 
new expiration date, new estimated cost, and if the dealer was changed, the new vendor code. The estimated cost is the actual cost for last year, unless for some reason last year has not been paid (and this can happen!), when the estimate for last year will be carried forward.

The fact that this operation is performed at the rate of six cards per minute, instead of from 50 to 100 on larger machines, is largely offset by the fact that at least four operations on as many machines will be required to complete the order and the new accounting cards. And with the relatively small quantities of cards involved, the make-ready time will often exceed the running time on the large machines. Another decided advantage of the cardatype over most accounting machines is the ability to create full punctuation and upper and lower case letters. It is also possible to create finished tables, complete with dollar marks, commas, and decimals, without punching the punctuation in the cards.

Disadvantages of the cardatype are the high level of maintenance required and the skill required in programming. The service required is related mostly to the typewriter and the automatic form feed; it is usually not serious, but may be annoying if service is not close at hand.

The cardatype is serial in operation rather than parallel (meaning that each character is read singly rather than that all characters on a card are read simultaneously, with each step requiring one tenth of a second. The program, and hence the wiring of the control panel, must take into account every step, and, except in the simplest programs, every alternative situation which may be anticipated. Once a program has been set up, actual operation is simple and can be learned by a clerk within an hour or so.

A book purchase request which has been verified and approved by the order department is the source document from which all punched card operations proceed in the University of Missouri sys- tem. Arrangement of items on the punched card follows the layout of the book purchase request for ease of punching. Cards are punched to represent each book purchase request; two or three cards are normal, but in some cases, a single card is sufficient. Each card in a set is numbered so that sequence and completeness may be checked by the cardatype.

Purchase orders and slips for various processes are prepared on the cardatype from the punched cards. Extra 3x5 slips are used for Library of Congress card orders, entry in the public catalog, numerical file, etc. Alternative procedures were considered, which, under other circumstances, might have been adopted. These would have used machines to create punched cards for accounting purposes as a by-product of manually typing purchase orders. Those employed might be a typewriter-card punch; or a typewriter-tape punch, (e.g., the Flexowriter), with a tape to card converter. If any of these alternatives had been used, only one card per title would have been required for accounting purposes and would have reflected only the first few words of the author and title.

Purchase orders, except for rush items, are issued only once each week. Before they are mailed, one of the slips for each title (with the legend "On Order") is filed in the public catalog, serving as a final check on duplication. At the same time, the IBM cards (called encumbrance cards) are used to post encumbrances to the budget ledger; thus, any item may be cancelled before mailing, either for lack of funds or because of unwanted duplication.

The IBM cards are filed in an Orders Outstanding file by vendor and order number. When invoices are received, they are routed through the accounting office. The Orders Outstanding cards are

(Continued on page 264) 
Automatic Records . . .

(Continued from page 232)

pulled to match invoices, and are inserted in the read unit of the carlatype. A control panel, wired for this particular purpose, enables the operator, by entering the actual invoice amount in the keyboard, to create a payment (Payables Distribution) card for each item, which includes all information from the encumbrance card being read. A total card (Accounts Payable) is prepared automatically for each invoice, proving both the vendor's footings and the operator's postings.

These Payables Distribution and Accounts Payable cards are held in a suspense file while the invoices, accompanied by the original encumbrance cards, are being checked in the order department. As the books are checked with invoices, the encumbrance cards are placed in the volume. The invoice is approved and returned to the accounting office. If an item is missing, a form notice of change of invoice is prepared and attached with the IBM cards to the approved invoice. The accounting office destroys the Detail Payment card for the undelivered item, corrects the Accounts Payable card, returns the encumbrance card to the Orders Out file, and sends the notice to the vendor.

A Balance Forward card for each of the 150 budget accounts comprising the book fund shows payments to date, orders outstanding, budget allocation, and unobligated balance. Each week the Payable Distribution cards for invoices approved are sorted by budget account, merged with the balance cards for active accounts and posted to the budget ledger using the cardatype. Actually, both new orders and payments are posted in the same operation. A new balance card is created for each active account.

The Payables Distribution cards are filed in a Paid but Not Cataloged file. When the book has been cataloged, the encumbrance cards placed in it at the time of invoice approval are returned to the accounting office. They are then matched on the collator with the payment cards which are transferred to a Paid and Cataloged file.

To this point, either the order procedure adopted or the alternatives which were rejected would have produced essentially identical results. It was the additional operations which follow that influenced the decision.

In early thinking, much weight was given to the possibility of using the IBM cards for temporary cataloging. The IBM cards would be used to prepare temporary entries for the catalog, using the order number as the temporary call number. Actually, for reasons not related to the procedures, little use has thus far been made of this possibility.

Claiming of undelivered orders is a useful by-product of the procedures adopted. The Orders Outstanding file is searched with the collator for delinquent items, and $3 \times 5$ slips are typed automatically for each item. These slips may be used to claim delivery of an item or to request invoices for items already delivered.

Another feature is the reordering of cancelled items. Under the system adopted, once cards have been punched for an item, it is possible to reproduce and alter them to reorder from any other source. This feature has been more useful than originally anticipated. More important, however, is the maintenance of an active quotation file. In this library, the quotation file had been a safe burial place for a request; if not favorably reported after one quotation request, an item was well nigh forgotten.

Under present procedures, whenever a book purchase request for an out-ofprint item is received without a secondhand catalog reference, the quotation procedure is instituted. IBM cards are punched in the normal way, except that no vendor is recorded. A three-part form 
is prepared for the item: a quotation request to be sent to an appropriate dealer, a slip for filing into the public catalog bearing the legend "Recommended for Purchase," and a card to be placed in the quotation file on which are recorded the dealers invited to quote.

The IBM cards are kept in lots by month of quotation. If an item is offered the cards are pulled and are used to create the purchase order. Cards remaining after four months are re-listed on a single-part form for sending to another dealer, and the IBM cards are advanced to the proper month.

Whenever an item on order is cancelled, it is entered in the quotation routine without any additional card punching. When an item has been in the procedure for a year, it is reviewed for further treatment. It may be cancelled outright, ordered in microfilm, ordered in facsimile, continued in the quotation procedure, or placed on a want list.

The want list differs from the quotation file in that a specific dealer is given exclusive (almost exclusive, that is) right to supply an item during the ensuing two years. If located at a price which meets the terms of the agreement with the dealer, it is sent without further paper work. The IBM cards in the file are used for all accounting operations.

In time, these procedures will be articulated with shelf listing, book marking, and circulation records to create a completely integrated automatic record system.

\section{STANDARD LIBRARY FURNITURE}

Accepted as the standard for durability and beauty in libraries throughout the country. Interesting and informative brochures on library furniture are available on request.

Illustrated: Our installation in the Broadmoor Junior High School, Merriam, Kansas.

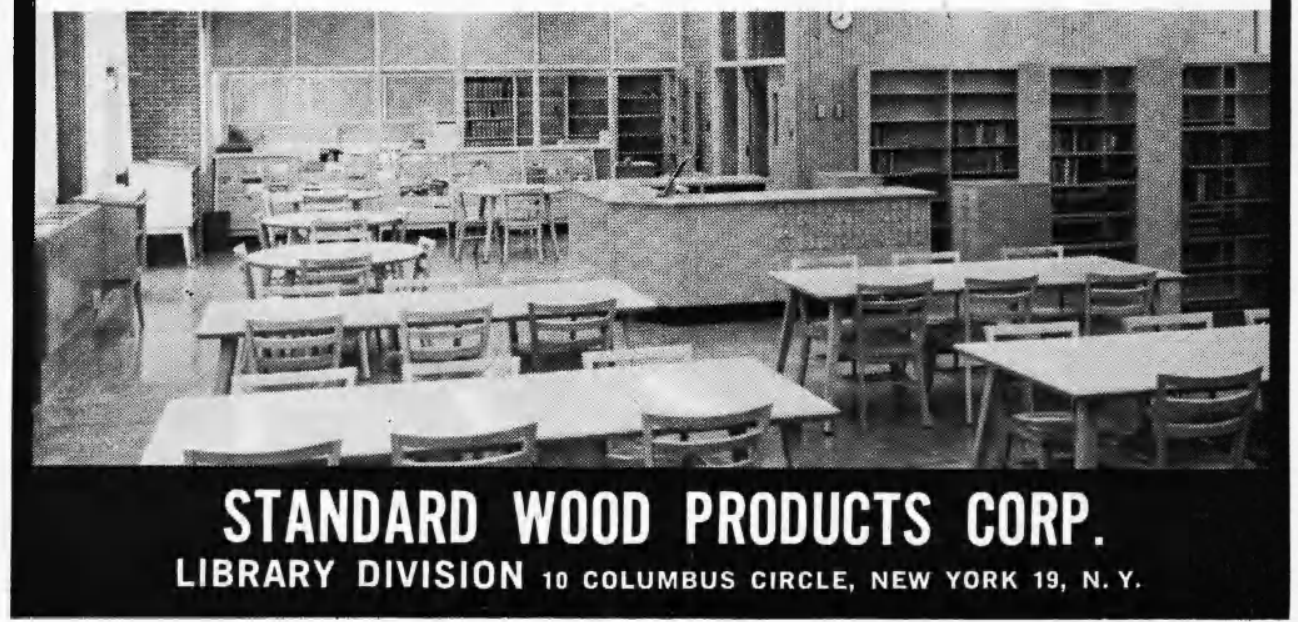

